\title{
Impact of 3D-culture on the expression of differentiation markers and hormone receptors in growth plate chondrocytes as compared to articular chondrocytes
}

\author{
CHRISTIAN ALBRECHT ${ }^{1,2}$, MAGDA HELMREICH ${ }^{3}$, BRIGITTE TICHY ${ }^{2}$, STEFAN MARLOVITS ${ }^{2}$, \\ ROBERTO PLASENZOTTI ${ }^{4}$, MONIKA EGERBACHER $^{3}$ and GABRIELE HAEUSLER ${ }^{1}$ \\ ${ }^{1}$ Department of Paediatrics, Medical University of Vienna, ${ }^{2}$ Department of Traumatology, \\ Center for Joint and Cartilage, Austrian Cluster for Tissue Regeneration, Medical University of Vienna, \\ Waehringer Guertel 18-20, 1090 Vienna; ${ }^{3}$ Department of Histology, University of Veterinary Medicine Vienna, \\ Veterinaerplatz 1, 1210 Vienna; ${ }^{4}$ Institute of Biomedical Research, Medical University of Vienna, \\ Waehringer Guertel 18-20, 1090 Vienna, Austria
}

Received November 12, 2008; Accepted December 29, 2008

DOI: $10.3892 /$ ijmm_00000138

\begin{abstract}
In this study we compared the expression of hormone receptors and markers of differentiation in growth plate chondrocytes (GPC) and articular chondrocytes (AC) under different culture conditions by real-time PCR and immunofluorescence. After one week of monolayer culture, porcine GPC and AC of 6-8-week-old piglets were either seeded in alginate beads or further grown in monolayer culture up to 5 weeks. During monolayer culture the expression of Col2, Col1, Col10, aggrecan, ER $\alpha$ and ER $\beta$ decreased dramatically, whereas culture in alginate beads restored an expression pattern similar to native tissue. The receptors $I G F-1 R, I G F-2 R$ and $G H R$ were, however, increased in monolayer culture compared to alginate culture or native tissue. The relative proportion of $E R \alpha$ and $E R \beta$ expression was different in GPC when compared to AC. All of our results on mRNA expression during culture in alginate beads were also verified to be translated to the protein level. Thus, the expression of hormone rereptors and differentiation markers were found to be highly influenced by culture conditions. Moreover, the porcine model is promising as defined by tissue availability, expression of relevant hormonal receptors and comparability to human conditions, in particular in the area of basic growth research.
\end{abstract}

Correspondence to: Dr Gabriele Haeusler, Department of Paediatrics, Medical University of Vienna, Waehringer Guertel 18-20, 1090 Vienna, Austria

E-mail: gabriele.haeusler@meduniwien.ac.at

Key words: chondrocytes, growth plate, articular cartilage, primary culture, hormone receptors

\section{Introduction}

Longitudinal growth is achieved by the coordinated proliferation and differentiation of chondrocytes within the epiphyseal growth plates. Growth plate chondrocytes (GPC) are the target of endocrine, paracrine, autocrine and even intracrine factors. The unique architecture of the growth plate is regulated by complex local signalling loops and so far unknown mechanisms. The impact of endocrine, metabolic and mechanical factors on the growth plate has been investigated extensively; special attention has been paid on the effects of classical endocrine pathways like the GH/IGF-I system and on local action of sex steroids (1-6).

The majority of studies were performed in vivo in various species, mainly rodents. In vitro, studies on the effect of hormones and growth factors on chondrocytes showed conflicting results and were often contradictory to the findings in vivo. Besides primary cell culture systems, also cell lines have been employed $(7,8)$. Culture conditions differed concerning culture medium, cell density and number of passages.

Monolayer culture represents a very unphysiological condition for chondrocytes and results in dramatic morphological and molecular-biological changes in the cells. This dedifferentiation process has already been well characterized by means of gene expression analysis of human articular chondrocytes (AC) $(9,10)$. However, different three dimensional cultures, for example alginate beads or other matrices, by enabling the maintenance of differentiation or rather the redifferentiation of human AC in vitro, were described (11-14).

The aim of our study was to establish a suitable, easy to use in vitro model for the investigation of GPC. In this study, we demonstrate that culture conditions have profound effects on chondrocyte differentiation as defined by specific expression of matrix molecules [collagen type II (Col2), type X (Col10), type I (Col1) and aggrecan] and in particular, on the expression of receptors relevant for growth regulation [insulin-like 
growth factor type I receptor (IGF-1R), type II receptor (IGF-2R), growth hormone receptor (GHR), estrogen receptor $\alpha(E R \alpha)$ and $\beta(E R \beta)]$. Interestingly, when comparing GPC with AC grown in the same culture conditions we found some fundamental differences in the expression of receptors, in particular estrogen receptors.

For our experiments, chondrocytes were derived from growth plates and articular cartilage of 6-8-week-old piglets, a developmental stage corresponding to childhood in the human and thus appropriate for studies of postnatal prepubertal growth.

\section{Materials and methods}

Isolation and monolayer culture of porcine GPC and AC Porcine growth plate and articular cartilage specimens were collected from the femur and tibia of 6-8-week-old piglets sacrificed in the course of other studies not related to the locomotor system performed at different Institutes (approved by the Ethics Board of the University of Veterinary Medicine, Vienna). Growth plates and articular cartilage from the same pig and extremity were used as native controls. Growth plates were dissected from surrounding bone and adjacent tissue and were isolated and cultivated in monolayer culture according to our standard operation procedure, as previously described (9). After one week expansion in monolayer culture cells were seeded in alginate $(1.25 \%$ sodium-alginate, Fluka, Deisenhofen, Germany in $0.9 \%$ saline solution; $4 \times 10^{6}$ cells $/ \mathrm{ml}$ ) or on chamber slides. Alginate beads were prepared by dropping alginate cell suspension through a $1000 \mu 1$ pipette into $\mathrm{CaCl}_{2}$-suspension (102 mM). The beads were cultured in DMEM with supplements described above.

RNA extraction and purification of chondrocytes cultivated in monolayer culture and alginate beads. Monolayer cells were harvested by adding $1 \mathrm{ml}$ of TRI Reagent ${ }^{\mathrm{TM}}$ (Sigma-Aldrich). Alginate beads were first dissolved in dissolving buffer $(55 \mathrm{mM}$ sodium citrate, $30 \mathrm{mM}$ EDTA, $150 \mathrm{mM} \mathrm{NaCl}$, pH 6.8). Then the liberated cells were collected, washed twice with PBS and dissolved in $1 \mathrm{ml}$ of TRI Reagent (Sigma-Aldrich). RNA isolation was performed according the standard protocol. For total RNA extraction from native cartilage, tissue was frozen in liquid nitrogen and ground using a mortar and pestle. Further steps were performed using the RNeasy ${ }^{\circledR}$ plant mini kit (Quiagen, Germany). The procedure for isolating total RNA was executed as described in the RNeasy mini handbook (Qiagen, Germany, 06/2001).

cDNA synthesis. Total RNA (0.1-1 $\mu \mathrm{g})$ was diluted with nuclease-free water to a volume of $15 \mu \mathrm{l}$ and $4 \mu \mathrm{l}$ iScript $^{\mathrm{TM}}$ reaction mix, as well as $1 \mu 1$ iScript Reverse Transcriptase were added (Bio-Rad Laboratories, CA, USA). The reaction mixture was incubated for $5 \mathrm{~min}$ at $25^{\circ} \mathrm{C}$, for $30 \mathrm{~min}$ at $40^{\circ} \mathrm{C}$, and for $5 \mathrm{~min}$ at $85^{\circ} \mathrm{C}$.

Primers and probes for quantitative analyses. Primers and probes for the respective porcine sequences were designed using Primer Express 3.0 (Applied Biosystems, CA, USA). To avoid amplification of genomic DNA, the probes were placed at the junction of two exons. Gene specificity of the primers
Table I. Description of the designed primers and probes.

\begin{tabular}{lll}
\hline mRNA template & & \multicolumn{1}{c}{ Primer sequence } \\
\hline Collal & & \\
& Left: & 5'-agaggagggccaagaagaag-3' \\
& Right: & 5'-atggtacctgaggccgttc-3' \\
& Probe: & 5'-agaagaagacatcccaccagtcacct-3'
\end{tabular}

Col2al

Left: 5 '-agacaggtgctgcaagtcttc-3'

Right: 5'-atcacctggtttcccacct-3'

Probe: 5'-atctggcttccagggacttcctg-3'

Colloal

Left: 5'-tttatactgagcaataccaaacacct-3'

Right: 5'-gaataccttgctctcctcttagtgat-3'

Probe: 5'-tccctacgccataaagagtaaaggt-3'

aggrecan

Left: $\quad 5^{\prime}$-ccttcatccegctacgac-3'

Right: 5'-gtcactgtctggatggtgatgt-3'

Probe: 5'-cacaggtgaagactttgtggacatcc-3'

$I G F-1 R$

Left: 5'-gccaagagtgagatcttgtacatt-3'

Right: 5'-ctatcagctgagaagaggagtttg-3'

Probe: 5'-caccaatgcttcagttccttccattc-3'

$I G F-2 R$

Left: 5'-ccaaagtggcgggaagact-3'

Right: 5'-cgcctccaaaataaatcaaggt-3'

Probe: 5'-cagaatcagaccctccggtactcgga-3'

GHR

Left: $\quad$ 5'-taccctactgtatcaagctgactagc-3'

Right: 5'-gtagagtccagttgaggccaat-3'

Probe: 5'-ttctccgttgaggaaatagtgcaacc-3'

$E R \alpha$

Left: 5'-ctcctcctcatcctgtctcac-3'

Right: 5'-gcacttcatgttgtacagatgct-3'

Probe: 5'-ttcaggcacatgagtaacaaaggcat-3'

$E R \beta$

Left: 5 '-tcgcactatgcggtaccca-3'

Right: 5'-cgaaagtgctatgaagtcggaa-3'

Probe: 5'-ttctctccgggagccacacttcacc-3'

and probes were confirmed by BLAST searches. Primers and probes were synthesized by Eurogentec S.A. (Seraing, Belgium) and were tested at concentrations of 50, 300, and $900 \mathrm{nM}$, choosing the combination that displayed the lowest $\mathrm{Ct}$ value. Primer sequences are shown in Table I.

Real-time PCR amplification and analysis. Real-time PCR amplification was performed using an Applied Biosystems 7500 fast real-time PCR system (Applied Biosystems). The master mix was based on SensiMix dU (Quantace, Berlin, Germany). The thermal cycling conditions comprised the initial steps at $50^{\circ} \mathrm{C}$ for $2 \mathrm{~min}$ and at $95^{\circ} \mathrm{C}$ for $10 \mathrm{~min}$. Amplification 

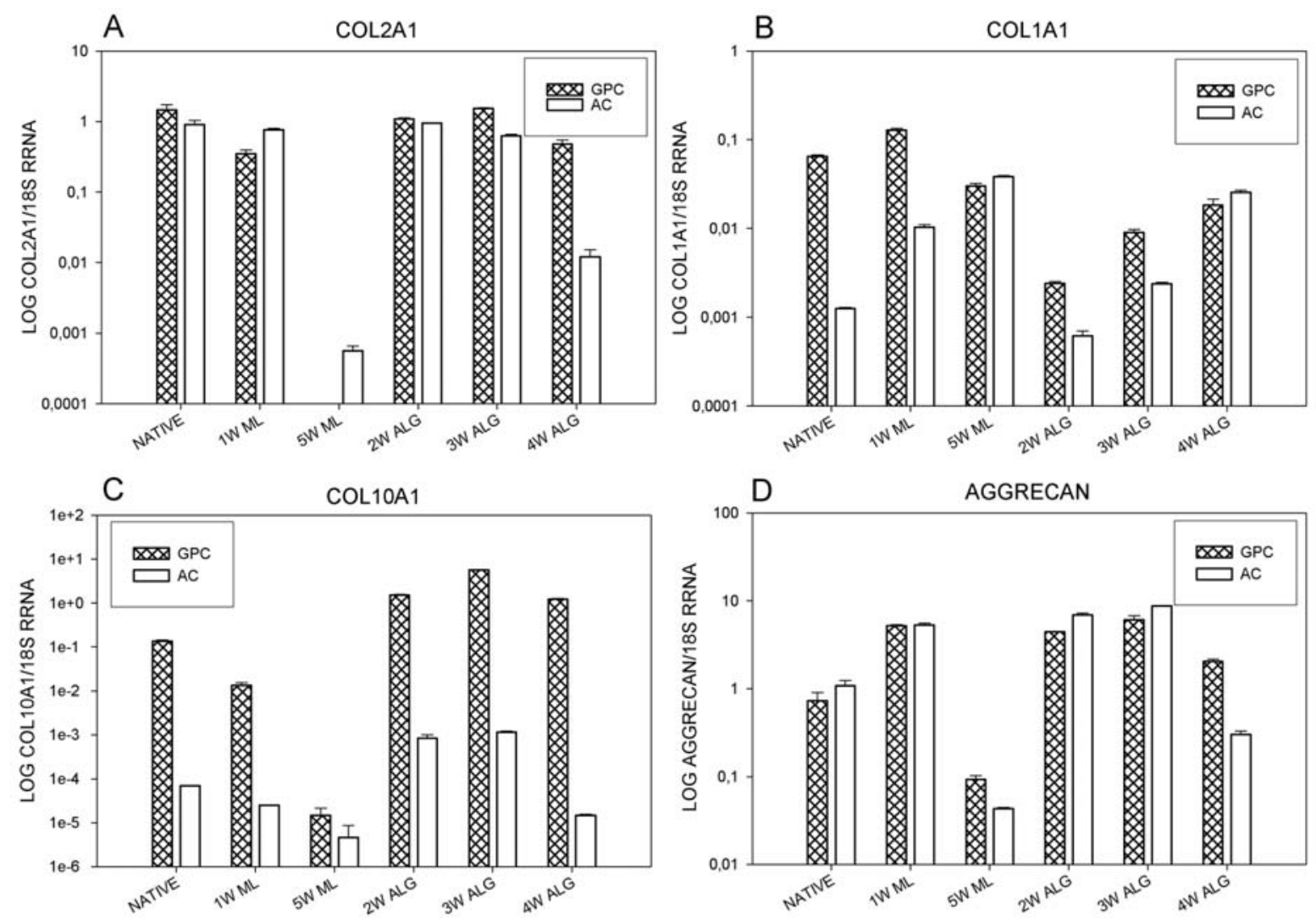

Figure 1. Real-time PCR analysis of growth plate chondrocytes (GPC) and articular chondrocytes (AC) in native tissue (native), monolayer culture (ML) and alginate beads (ALG) for Col2al (A), Collal (B), Colloal (C) and aggrecan (D). Gene expression was normalized to 18S rRNA expression.

of the cDNA products was performed with 40 PCR cycles, consisting of a denaturation step at $95^{\circ} \mathrm{C}$ for $15 \mathrm{sec}$ and an extension step at $60^{\circ} \mathrm{C}$ for $1 \mathrm{~min}$. $18 S$ rRNA was chosen as the internal standard, using the predeveloped TaqMan ${ }^{\circledR}$ assay (Applied Biosystems). All cDNA samples $(2.4 \mu \mathrm{l}$ in $20 \mu \mathrm{l})$ were analyzed in triplicate. The final numeric value was calculated as the ratio of the gene to $18 S$ rRNA and was expressed in arbitrary units.

Histology and immunohistochemistry. Specimens from the contralateral corresponding growth plates including surrounding bone and articular tissue were fixed in $4 \%$ buffered formalin and decalcified in 8\% EDTA. In addition, immunohistochemical staining of some proteins (ER $\alpha, E R \beta$, IGF-1R, IGF-2R) was carried out after dissection of growth plates from surrounding structures without decalcification and after fixation in methacarn. Alginate beads were fixed in methacarn. Sections $(4 \mu \mathrm{m})$ were cut and brought on APES/ glutaraldehyde-coated slides. Chondrocytes cultivated on chamber slides (Nalge NUNC Intern., Rochester, NY, USA) were fixed in $4 \%$ buffered formalin. Various pretreatments were necessary for antigen retrieval before applying the primary antibody. For Col2 and Col10, sections were digested with hyaluronidase $(0.2 \mathrm{mg} / \mathrm{ml}$, alginate bead sections for $60 \mathrm{~min}$, tissue sections for $1-2 \mathrm{~h}$ at $37^{\circ} \mathrm{C}$ ) followed by pepsin/ $0.01 \mathrm{~N} \mathrm{HCl}\left(0.5 \mathrm{mg} / \mathrm{ml}, 30 \mathrm{~min} 37^{\circ} \mathrm{C}\right)$, for Col1 and aggrecan with pepsin $0.05 \mathrm{M}$ acetic acid $(0.5 \mathrm{mg} / \mathrm{ml}$, alginate bead sections for $30 \mathrm{~min}$, tissue sections for $1-2 \mathrm{~h}$ at $37^{\circ} \mathrm{C}$ ). Cells on chamber slides were permeabilized with $0.2 \%$ Triton $\mathrm{X}-100$ in PBS for $10 \mathrm{~min}$ at $4^{\circ} \mathrm{C}$ and pretreated by hyaluronidase $\left(0.2 \mathrm{mg} / \mathrm{ml}, 10 \mathrm{~min}\right.$ at $\left.37^{\circ} \mathrm{C}\right)$. Detection of IGF-1R and IGF-2R on tissue sections and alginate beads required pretreatment in $0.001 \mathrm{M}$ EDTA for $20 \mathrm{~min}$ at $96^{\circ} \mathrm{C}$, and $\mathrm{ER} \alpha$ and $\mathrm{ER} \beta$ in citrate buffer, $\mathrm{pH} 6.0$ for $20 \mathrm{~min}$ at $96^{\circ} \mathrm{C}$.

Primary antibodies were applied at $4^{\circ} \mathrm{C}$ overnight. Antibodies used for staining of Col1, Col2, Col10, aggrecan, IGF-1R and $-2 \mathrm{R}, \mathrm{ER} \alpha$ and ER $\beta$ are given in Table II.

Secondary antibodies were Alexa mouse 488, Alexa goat 488, and Alexa rabbit 488 (Molecular Probes, Eugene, OR, USA). Sections were counterstained with DAPI nuclear stain (Molecular Probes). Native growth plates served as positive controls, negative controls were performed by omitting the primary antibody.

Statistical analysis. All samples were assayed by real-time PCR in triplicates. The values were log transformed and reported as the mean $\pm \mathrm{SD}$ of the real-time PCR analyses.

\section{Results}

Expression patterns in GPC. Col2 expression dramatically decreased during monolayer culture and was even not detected any more after 5 weeks of monolayer culture (Fig. 1A). Chondrocytes in alginate beads showed completely different characteristics; even after four weeks the Col2 expression level was similar to that of native growth plates. In monolayer culture Coll mRNA expression was very similar to native growth plates (Fig. 1B). After two weeks alginate 
Table II. Antibodies used in this study.

\begin{tabular}{|c|c|c|c|c|}
\hline Antibody & Supplier & Clone & Dilution & Host \\
\hline Col1 & Southern Biotech Birmingham, AL, USA & Polyclonal & $1: 30$ & Goat \\
\hline Col2 & NeoMarkers, Fremont, CA, USA & $2 \mathrm{~B} 1.5$ & $1: 50$ & Mouse \\
\hline Col10 & Quartett, Berlin, Germany & X53 & $1: 50$ & Mouse \\
\hline aggrecan & ABR, Golden, CO, USA & $\mathrm{BC}-3$ & $1: 30$ & Mouse \\
\hline IGF-1R & NeoMarkers, Fremont, CA, USA & Polyclonal & $1: 50$ & Rabbit \\
\hline IGF-2R & R\&D Systems, Wiesbaden-Nordenstadt, Germany & Polyclonal & $1: 50$ & Goat \\
\hline $\mathrm{ER} \alpha$ & Zymed Laboratories, Southern San Francisco, CA, USA & Polyclonal & $1: 150$ & Rabbit \\
\hline $\mathrm{ER} ß$ & Upstate. Lake Placid, NY, USA & Polyclonal & $1: 50$ & Rabbit \\
\hline
\end{tabular}
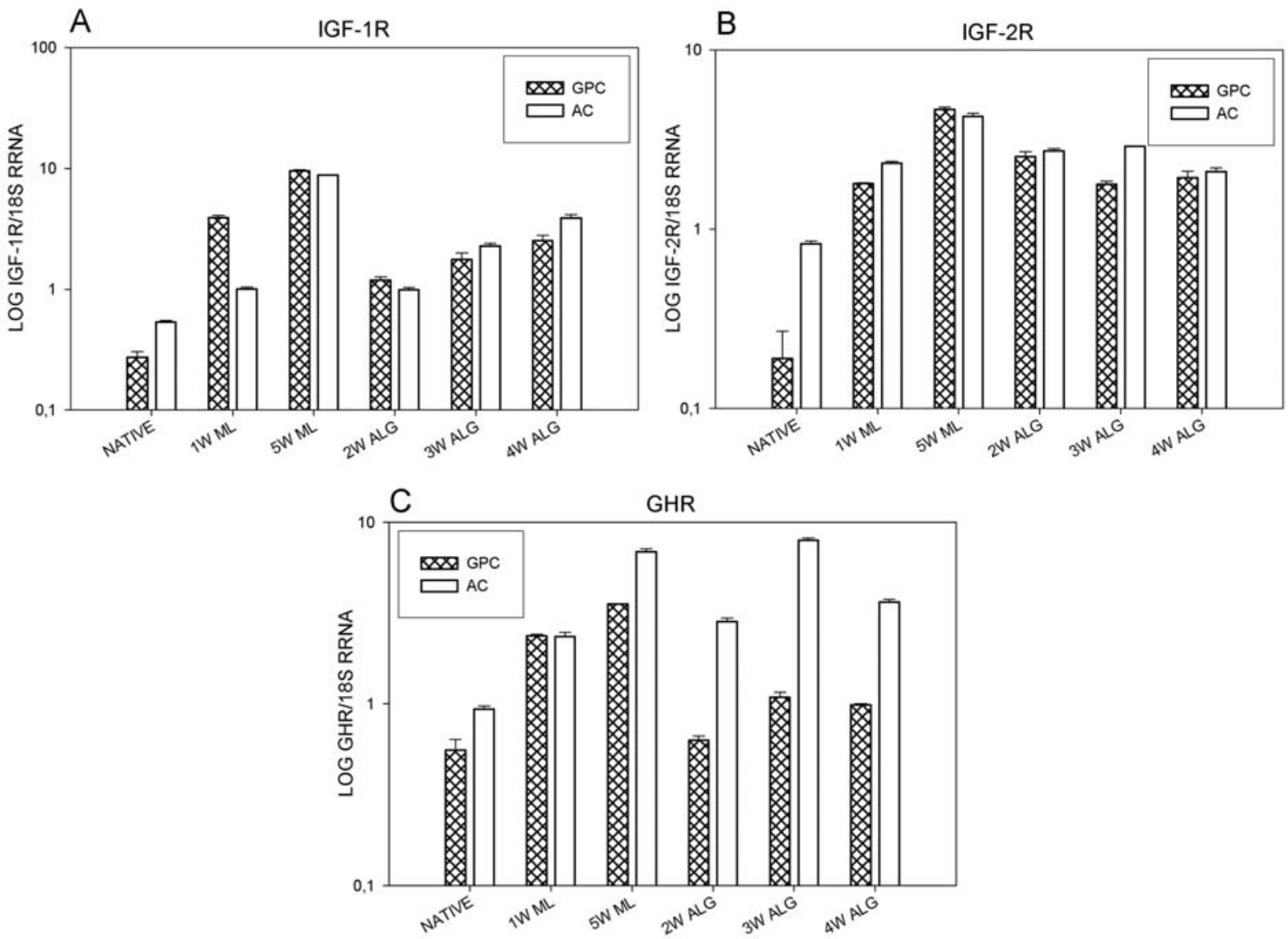

Figure 2. Real-time PCR analysis of growth plate chondrocytes (GPC) and articular chondrocytes (AC) in native tissue (native), monolayer culture (ML) and alginate beads (ALG) for $I G F-1 R(\mathrm{~A}), I G F-2 R(\mathrm{~B})$ and $G H R(\mathrm{C})$. Gene expression was normalized to $18 S \mathrm{~S} R N A$ expression.

culture Coll expression was decreased $>20$-fold in comparison with native cartilage. However, during the next two weeks alginate culture Coll expression increased (8-fold) and converged to levels of native growth plates. Collo expression also dramatically decreased during monolayer culture $\left(\sim\right.$ factor $\left.10^{-4}\right)$ (Fig. 1C). Again, 3-dimensional culture restored expression in native tissue already after 2 weeks with maintenance of expression for the period of 4 weeks. After an increase (7-fold) at one week of monolayer culture, aggrecan expression was decreased during the following 4 weeks (56-fold) (Fig. 1D). In alginate bead chondrocytes showed slightly increased aggrecan expression levels (5.7 \pm 2.8 -fold) in comparison with native growth plates.

Real-time PCR revealed an increase of $I G F-I R, I G F-2 R$ and $G H R$ during monolayer culture (Fig. 2). During cultivation in alginate beads, $I G F I-R$ and $G H R$ mRNA expression was clearly downregulated, however to levels still higher than in native tissue. This expression pattern was also found for the $I G F-2 R$, albeit less dramatic.

Both estrogen receptors $E R \alpha$ and $E R \beta$ could be detected in GPC. Due to their very low expression and the limited amount of native growth plate material, we were not able to detect $E R \alpha$ 

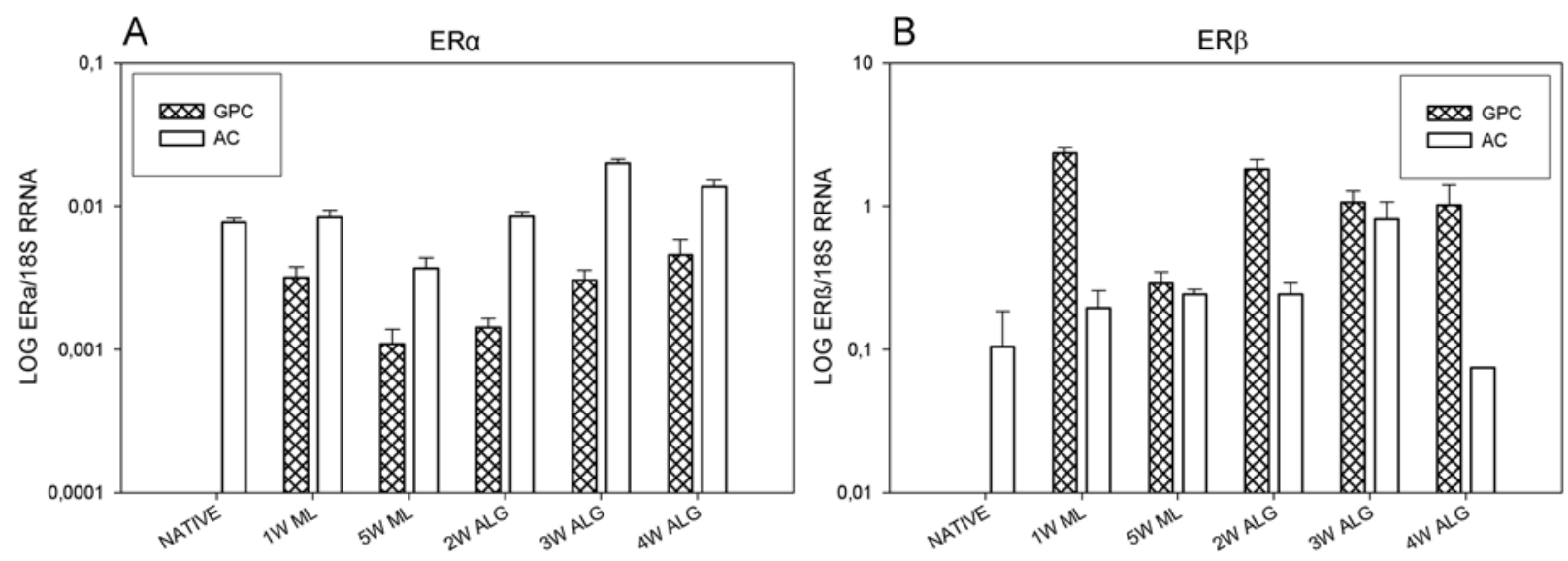

Figure 3. Real-time PCR analysis of growth plate chondrocytes (GPC) and articular chondrocytes (AC) in native tissue (native), monolayer culture (ML) and alginate beads (ALG) for ERa (A) and $E R \beta(\mathrm{B})$. Gene expression was normalized to $18 S \mathrm{rRNA}$ expression.

and $E R \beta$ in the native growth plates used for the comparison with monolayer and alginate culture. However, it became evident, that $E R \alpha$ as well as $E R \beta$ expression decreased from one week monolayer culture to five weeks monolayer and the expression levels were restored after chondrocytes were seeded into alginate beads (Fig. 3).

Expression patterns in AC. Coll expression was 52-fold lower in native articular cartilage when compared to growth plates (Fig. 1B). Due to a one-sided upregulation of Coll in AC Coll expression was even equal between GPC and AC after five weeks monolayer culture. A similar effect was seen in alginate culture, where the difference between Coll expression in GPC and AC declined over time. Col2 expression in GPC and $\mathrm{AC}$ differed only after five weeks of monolayer culture, where no Col2 expression was detected in GPC and in four weeks of alginate culture, where Col2 expression was higher in GPC than in AC (40-fold) (Fig. 1A). Changes in aggrecan expression mimicked the dynamics found in GPC (Fig. 1D). The highest difference in gene expression of GPC and AC was found for CollO (Fig. 1C). Its expression was consistently higher in GPC (up to 8460-fold) than in AC. The lowest difference (3-fold) was found after five weeks monolayer culture.

Whereas GPC and AC showed almost equal expression of $I G F-1 R$ in alginate beads and five-week monolayer culture, $I G F-1 R$ expression was higher in native articular cartilage than in growth plates (4-fold) and in GPC than in AC after one week monolayer culture (2-fold) (Fig. 2A). IGF-2R expression differed only in native samples, where it was higher expressed in articular cartilage than in growth plates (4-fold) (Fig. 2B). With the exception of one week monolayer culture, expression of GHR was higher in AC when compared to GPC, this difference was most obvious during cultivation in alginate beads (up to 7-fold) (Fig. 2C) .

Analysis of the estrogen receptors in GPC and AC revealed different results depending on the analysed subform (Fig. 3). Due to the missing values for the native growth plates, as mentioned above, the native samples could not be evaluated. In the other samples $E R \alpha$ expression was always higher in AC than GPC (3-7-fold). By contrast $E R \beta$ was expressed at higher levels by GPC (up to 14-fold) in most samples. The increase in both $E R \alpha$ and $E R \beta$ during 3-dimensional culture when compared to monolayer was also seen in AC.

Immunohistochemistry. Cultivation of chondrocytes in monolayer led to a decrease of the cartilage-specific marker protein $\mathrm{Col} 2$ and an increase of Col1 synthesis. Col10 and aggrecan production was low to not detectable in dedifferentiated chondrocytes after 2 weeks in monolayer. Chondrocytes cultured in alginate beads for 3 weeks showed strong staining for Col2 and aggrecan, weak staining for Col1 and Col10. This general staining pattern was true for GPC as well as AC with the exception of Coll and Col10, as some cells $(<10 \%)$ showed positive staining for both matrix proteins in alginate beads of GPC (Fig. 4).

Staining for IGF-1R and IGF-2R showed moderate to strong positive reaction in the cytoplasma and membrane of $\sim 70-80 \%$ of the chondrocytes cultivated for 3 weeks in alginate beads. No difference was detectable between GPC and AC, similar to native tissue (Fig. 5).

The detection of ER $\alpha$ showed a continuous decrease of positive cells (weak nuclear staining) to $<10 \%$ after 2 weeks in monolayer cultures (data not shown). Cultivation in alginate beads revealed weak to moderate nuclear staining in $~ 50-60 \%$ of chondrocytes. When comparing GPC and AC, ER $\alpha$ was generally weaker in GPC than in AC (Fig. 6), which was comparable with native tissue staining (data not shown). In monolayer culture, staining intensity as well as the number of ERß positive chondrocytes decreased over time of cultivation. Cells $(<10 \%)$ showed moderate to strong nuclear staining and moderate cytoplasmic staining after 2 weeks of monolayer culture. GPC were generally stained more intensely for ERß when compared to AC (data not shown). Nuclear as well as cytoplasmic staining for ERß was generally stronger and was found in nearly all cells in alginate bead sections (Fig. 6).

\section{Discussion}

In this study we have for the first time shown that expression patterns of hormone receptors display distinct dynamic patterns in different in vitro cultivation conditions. mRNA expression and protein synthesis of cartilage specific matrix molecules displayed similar dynamic patterns in growth plate 

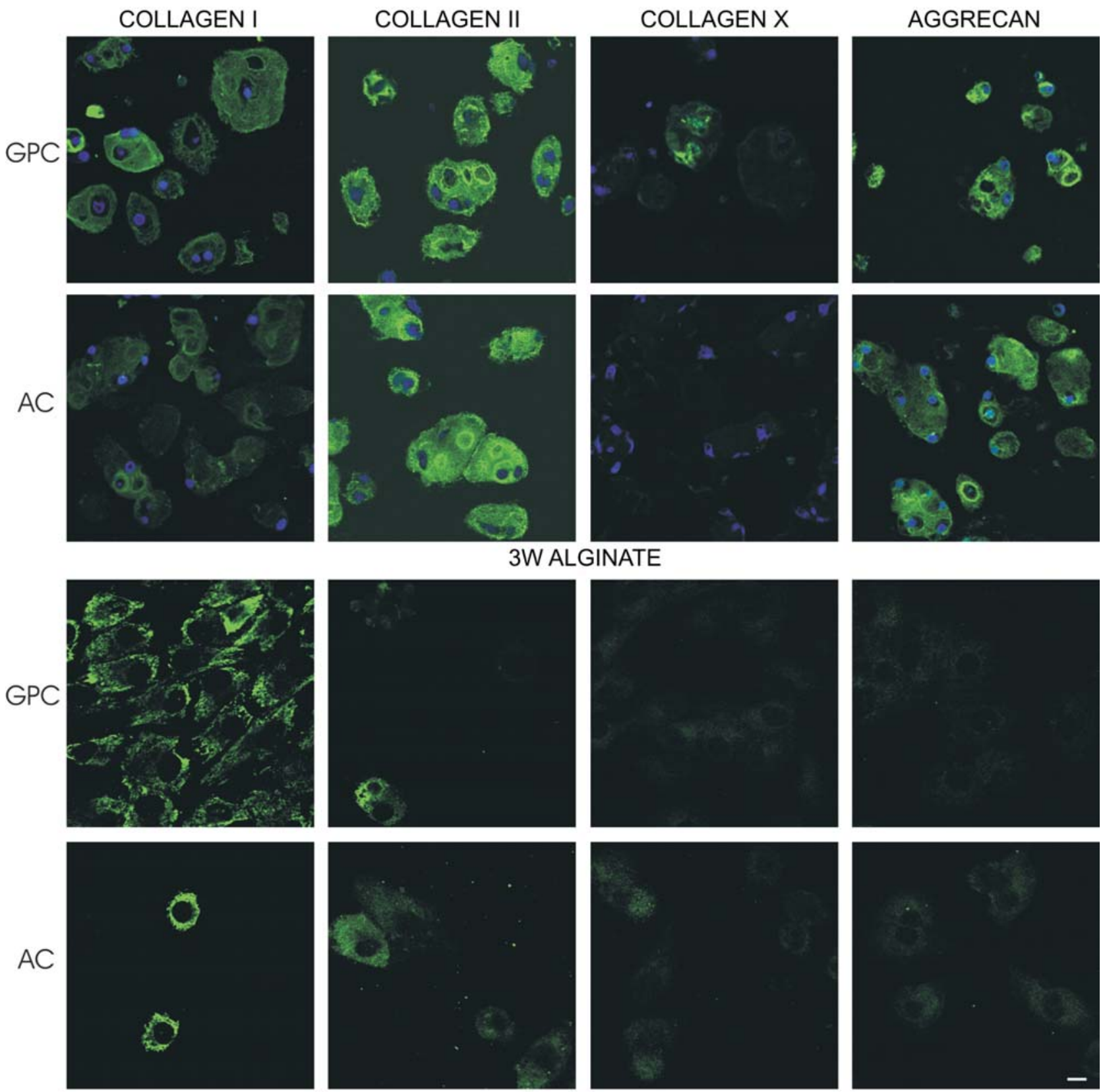

2W MONOLAYER

Figure 4. Confocal laser micrographs of growth plate (GPC) and articular chondrocytes (AC) cultivated in alginate and as monolayer, detection of matrix proteins by IHC (FITC in green, DAPI nuclear staining in blue). Scale bar $=10 \mu \mathrm{m}$.

and articular derived chondrocytes, as did the receptors for IGFs and GH. However, ER $\alpha$ and ERß, whilst found to be most sensible towards culture conditions, also displayed striking differences between GPC and AC.

So far, in vitro studies on growth and chondrocyte regulation, in particular, investigations on the effect and mechanism of relevant hormones on the tissue levels have been studied in primary chondrocyte cultures of rat or bovine origin (15-17) or human chondrogenic cell lines (8) under various culture conditions. Due to the poor availability of growth plate tissue, the developmental stage in the few studies with human chondrocytes was either fetal (18), or pubertal (19). Chondrocytes have either been isolated from the epiphyseal growth plate of long bones, the costochondral junction, or the iliac crest. However, different proliferation profiles from different joints have been found in different skeletal regions, and it has been recommended to perform in vitro studies using the species and site where subsequent in vivo studies are planned (20).

In attempts to define a suitable animal model for research, some medical disciplines have already chosen the porcine model for many reasons. It has already been stated (21) that the growing piglet is a good model for growing children (22), when compared to the growth plate in rodents, the pig growth plate more closely resembles the human growth plate in terms of cellular numbers in the different zones, cell kinetics and patterns of closure (23).

It is well established that the extracellular matrix (ECM) plays a role in regulating the differentiated phenotype of cells (24). Seeding of isolated articular chondrocytes in different 


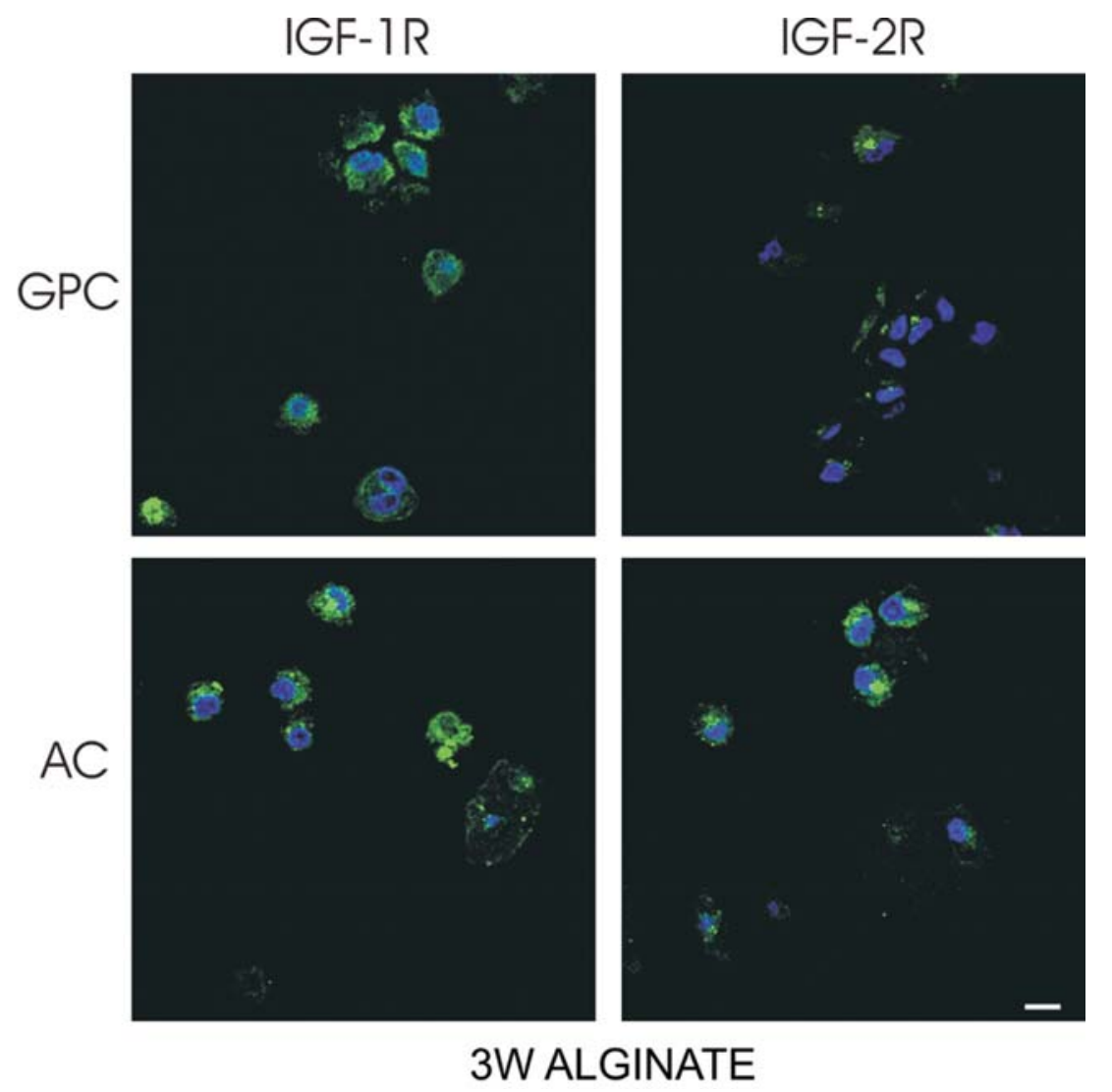

Figure 5. Confocal laser micrographs of growth plate (GPC) and articular chondrocytes (AC) cultivated in alginate for 3 weeks. Immunohistochemical detection of IGF-1R and IGF-2R showed no difference between GPC and AC. Scale bar $=10 \mu \mathrm{m}$.

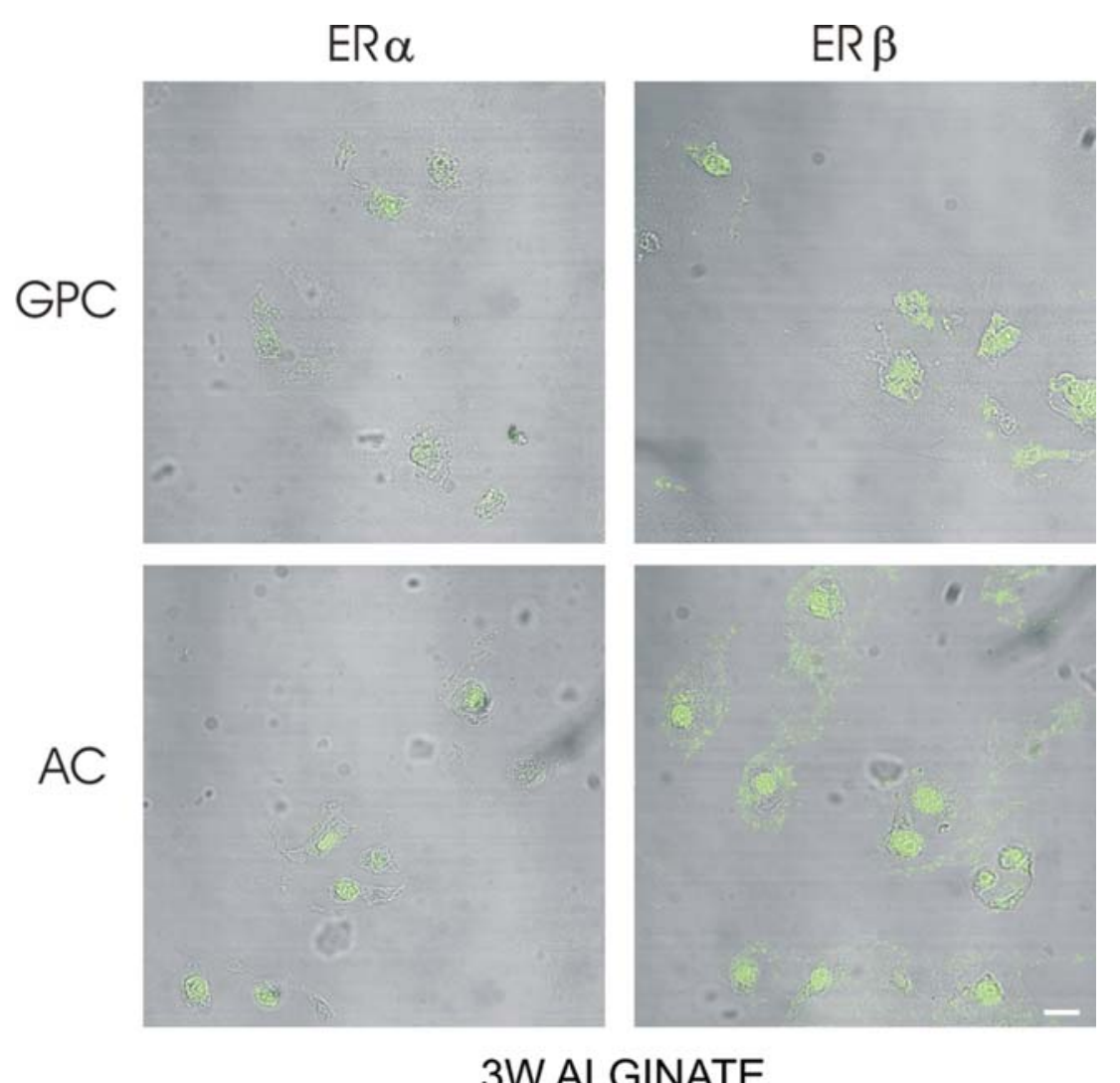

Figure 6. Confocal laser micrographs of growth plate (GPC) and articular chondrocytes (AC) cultivated in alginate. Nuclear staining for ER $\alpha$ was generally weaker in GPC than in AC. Detection of ERß showed nuclear and cytoplasmic staining that was stronger in GPC than AC. Scale bar $=10 \mu \mathrm{m}$. 
matrices has been shown to restore differentiation (11-13) and the differentiated phenotype was stable in these 3D culture systems for months in vitro (25). To our knowledge, this 3 dimensional culture system has not been applied in growth plate derived chondrocytes before.

Due to its exclusive appearance in cartilage, $\mathrm{Col} 2$ has been used for a long time to characterize the differentiation status of chondrocytes, especially in AC. A downregulation of Col2 corresponds to a dedifferentiation process, which happens notoriously during monolayer culture of $\mathrm{AC}$. We found the same dedifferentiation process for GPC, even to a higher extent.

In our model Col10 proved to be a reliable differentiation marker of GPC. Although its expression was higher several decimal powers in GPC, the dynamic of changes during different culture conditions was very similar to AC. The expression patterns during alginate culture impressively demonstrated that the differentiation capacity of chondrocytes subsisted in $3 \mathrm{D}$ culture even after a long period of time.

In growth plates Coll expression is limited to hypertrophic chondrocytes or rather cells in the region of vascular invasion (26). The surprising high amount of Coll in the native growth plates in comparison with articular cartilage, which contains some Coll in the superficial zone (27), could be explained by the proportion of Col1 positive cells derived from the resorption zone of the growth plate (26). Whereas the upregulation of Coll in AC can be clearly interpreted as a sign of dedifferentiation, two overlapping processes might be responsible for the unchanged Coll expression in GPC during monolayer culture, the increase of dedifferentiatied cells producing Coll on the one hand and the decrease of Coll producing cells originating from the resorption front (26) on the other.

Receptors $I G F 1 R, I G F 2 R$ and $G H R$ were all upregulated during monolayer culture, both in GPC or in AC. The high expression of these receptors might demonstrate a survival mechanism of the cells and thus be misleading when interpreted as a growth related phenomenon. By contrast, chondrocytes seeded in alginate beads showed a much more physiological expression of these receptors. Interestingly, when comparing GPC and AC, both exhibit a very similar expression profile for growth factor receptors suggesting that AC can be used as an additional source for prolilferation studies.

$\mathrm{ER} \alpha$ and ERß have been located in several mammalian growth plates including the human $(6,28,29)$ and articular cartilage (30). The presence of ER is an important requirement for in vitro studies on the mechanisms of estrogen action on growth. It is well appreciated that studies with ER in primary cultures is extremely difficult due to the low expression of ER and rapid downregulation in culture. In mesenchymal stem cells differentiating into chondrocytes, an extremely low expression of ER, rapid downregulation during culture and hardly any response to estrogen has been observed (M. Karperien, personal communication). We demonstrated in this study that both estrogen receptors are expressed by porcine chondrocytes, although highly dependent on the culture condition used. Once more this indicated that monolayer culture is not an adequate culture condition for studying effects of estrogens on chondrocyte regulation and alginate culture is superior in this respect. A distinct difference between GPC and $\mathrm{AC}$ became apparent when we compared the relative proportion of $E R \alpha$ and $E R \beta$ expression. Whereas $E R \alpha$ was always expressed at lower levels by GPC than AC, $E R \beta$ expression exhibited similar or rather increased values in GPC. These differences on the mRNA level were also confirmed on the protein level by the immunohistochemical staining results.

Summarizing our results, we demonstrated that expression patterns of hormone receptors and relevant matrix proteins are influenced by culture conditions both on the mRNA and on the protein level. On the basis of our results we propose that in studies designed to investigate differentiation processes or estrogen action, a culture system in which chondrocytes are embedded in matrix should be favoured. The porcine model is promising, as tissue is easily available and this species is more similar to human in many respects than rodent or avian. This is particular relevant in growth research where tissue has to be available in sufficient amounts in all developmental stages including the postnatal, prepubertal period, in which human tissue is fairly impossible to be obtained. Moreover, we have shown that chondrocytes derived from articular regions, due to the similarities in expression patterns of receptors of the GH/IGF axis, fit for studies of chondrocyte proliferation, at least at the rather early developmental stage investigated in this study. However, specific expression patterns of ERs seem to demand the use of growth plate derived tissue.

\section{Acknowledgements}

This study was in part sponsored by Novo Nordisk Pharma Austria.

\section{References}

1. Isaksson OG, Lindahl A, Nilsson A and Isgaard J: Mechanism of the stimulatory effect of growth hormone on longitudinal bone growth. Endocr Rev 8: 426-438, 1987.

2. Le Roith D, Bondy C, Yakar S, Liu JL and Butler A: The somatomedin hypothesis: 2001. Endocr Rev 22: 53-74, 2001.

3. Hunziker EB, Wagner J and Zapf J: Differential effects of insulin-like growth factor I and growth hormone on developmental stages of rat growth plate chondrocytes in vivo. J Clin Invest 93: 1078-1086, 1994.

4. Green H, Morikawa M and Nixon T: A dual effector theory of growth-hormone action. Differentiation 29: 195-198, 1985.

5. Morishima A, Grumbach MM, Simpson ER, Fisher C and Qin K: Aromatase deficiency in male and female siblings caused by a novel mutation and the physiological role of estrogens. J Clin Endocrinol Metab 80: 3689-3698, 1995.

6. van der Eerden BC, Karperien M and Wit JM: The estrogen receptor in the growth plate: implications for pubertal growth. J Pediatr Endocrinol Metab 14 (Suppl 6): 1527-1533, 2001.

7. Takigawa M, Tajima K, Pan HO, et al: Establishment of a clonal human chondrosarcoma cell line with cartilage phenotypes. Cancer Res 49: 3996-4002, 1989.

8. Chagin AS, Chrysis D, Takigawa M, Ritzen EM and Savendahl L: Locally produced estrogen promotes fetal rat metatarsal bone growth; an effect mediated through increased chondrocyte proliferation and decreased apoptosis. J Endocrinol 188: 193-203, 2006.

9. Marlovits S, Hombauer M, Tamandl D, Vecsei V and Schlegel W: Quantitative analysis of gene expression in human articular chondrocytes in monolayer culture. Int J Mol Med 13: 281-287, 2004.

10. Marlovits S, Hombauer M, Truppe M, Vecsei V and Schlegel W: Changes in the ratio of type-I and type-II collagen expression during monolayer culture of human chondrocytes. J Bone Joint Surg Br 86: 286-295, 2004. 
11. Bonaventure J, Kadhom N, Cohen-Solal L, et al: Reexpression of cartilage-specific genes by dedifferentiated human articular chondrocytes cultured in alginate beads. Exp Cell Res 212: 97-104, 1994.

12. Gavenis K, Schmidt-Rohlfing B, Mueller-Rath R, Andereya S and Schneider U: In vitro comparison of six different matrix systems for the cultivation of human chondrocytes. In Vitro Cell Dev Biol Anim 42: 159-167, 2006.

13. Grigolo B, Lisignoli G, Piacentini A, et al: Evidence for redifferentiation of human chondrocytes grown on a hyaluronanbased biomaterial (HYAff 11): molecular, immunohistochemical and ultrastructural analysis. Biomaterials 23: 1187-1195, 2002.

14. Schlegel W, Nurnberger S, Hombauer M, Albrecht C, Vecsei V and Marlovits S: Scaffold-dependent differentiation of human articular chondrocytes. Int J Mol Med 22: 691-699, 2008.

15. Nasatzky E, Schwartz Z, Boyan BD, Soskolne WA and Ornoy A: Sex-dependent effects of 17-beta-estradiol on chondrocyte differentiation in culture. J Cell Physiol 154: 359-367, 1993.

16. Rodd C, Jourdain N and Alini M: Action of estradiol on epiphyseal growth plate chondrocytes. Calcif Tissue Int 75: 214-224, 2004

17. Somjen D, Weisman Y, Mor Z, Harell A and Kaye AM: Regulation of proliferation of rat cartilage and bone by sex steroid hormones. J Steroid Biochem Mol Biol 40: 717-723, 1991.

18. Carrascosa A, Audi L and Ballabriga A: Morphologic and metabolic development of human fetal epiphyseal chondrocytes in primary culture. Pediatr Res 19: 720-727, 1985.

19. Saggese G, Federico G and Cinquanta L: In vitro effects of growth hormone and other hormones on chondrocytes and osteoblast-like cells. Acta Paediatr 82 (Suppl 391): 54-60, 1993.

20. Akens MK and Hurtig MB: Influence of species and anatomical location on chondrocyte expansion. BMC Musculoskelet Disord 6: 23,2005
21. Smink JJ, Koedam JA, Koster JG and van Buul-Offers SC: Dexamethasone-induced growth inhibition of porcine growth plate chondrocytes is accompanied by changes in levels of IGF axis components. J Endocrinol 174: 343-352, 2002.

22. Miller ER and Ullrey DE: The pig as a model for human nutrition. Annu Rev Nutr 7: 361-382, 1987

23. Thurston MN and Kember NF: In vitro thymidine labelling in human and porcine growth plates. Cell Tissue Kinet 18: 575-582, 1985.

24. Adams JC and Watt FM: Regulation of development and differentiation by the extracellular matrix. Development 117 : 1183-1198, 1993.

25. Lemare F, Steimberg N, Le Griel C, Demignot S and Adolphe M: Dedifferentiated chondrocytes cultured in alginate beads: restoration of the differentiated phenotype and of the metabolic responses to interleukin-1beta. J Cell Physiol 176: 303-313, 1998.

26. Sandell LJ, Sugai JV and Trippel SB: Expression of collagens I, II, $\mathrm{X}$, and $\mathrm{XI}$ and aggrecan mRNAs by bovine growth plate chondrocytes in situ. J Orthop Res 12: 1-14, 1994.

27. Stanescu V, Stanescu R and Maroteaux P: Differences in distribution of type I and type II collagens in the superficial and intermediary zones of articular cartilage. C R Acad Sci Hebd Seances Acad Sci D 283: 279-282, 1976 .

28. Egerbacher M, Helmreich M, Rossmanith W and Haeusler G: Estrogen receptor-alpha and estrogen receptor-beta are present in the human growth plate in childhood and adolescence, in identical distribution. Horm Res 58: 99-103, 2002.

29. Nilsson O, Abad V, Chrysis D, Ritzen EM, Savendahl L and Baron J: Estrogen receptor-alpha and -beta are expressed throughout postnatal development in the rat and rabbit growth plate. J Endocrinol 173: 407-414, 2002.

30. Richmond RS, Carlson CS, Register TC, Shanker G and Loeser RF: Functional estrogen receptors in adult articular cartilage: estrogen replacement therapy increases chondrocyte synthesis of proteoglycans and insulin-like growth factor binding protein 2. Arthritis Rheum 43: 2081-2090, 2000. 